\title{
Introduction from our guest editors
}

\section{Special issue: New theoretical and empirical takes on Norwegian: focusing on acquisition, variation and attrition}

\author{
Björn Lundquist ${ }^{1} \cdot$ Anne Dahl ${ }^{2}$
}

Published online: 28 June 2019

(C) Springer Nature B.V. 2019

The idea of this special issue of the Journal of Comparative Germanic Linguistics was born at a meeting at Stiklestad near Trondheim in the summer of 2016, where linguists from UiT The Arctic University of Norway and Norwegian University of Science and Technology (NTNU) came together to establish a joint research group on language acquisition, language variation and language attrition. The name of the group is AcqVA: Acquisition, Variation and Attrition, and it is currently led by Marit Westergaard (UiT/NTNU) and Terje Lohndal (NTNU/UiT). Today the group consists of more than 40 members from UiT and NTNU. The group is anchored in a formal generative tradition, and the aim of the group is to address some of the core questions concerning the nature of mental grammars: how are they acquired, what is the range of variation between speakers within and across individual languages, and how do they change over the lifespan. The focus is on language acquisition and development in different types of multilingual/multilectal contexts, thus stepping away from the fully developed "stable" adult L1 grammar as the prime source of data for modeling the language faculty. The choice of focus is motivated by several factors. First, in today's globalized world most people encounter and acquire more than one language, making multilingualism the norm. Secondly, by comparing

Special Issue Editors: Björn Lundquist and Anne Dahl.

Björn Lundquist

bjorn.lundquist@uit.no

Anne Dahl

anne.j.dahl@ntnu.no

1 Institute of Language and Culture, Faculty of Humanities, Social Sciences and Education, UiT, The Arctic University of Norway, 9037 Troms $\emptyset$, Norway

2 Department of Language and Literature, Faculty of Humanities, NTNU - Norwegian University of Science and Technology, Trondheim, Norway 
different groups of speakers of a language, e.g. heritage speakers, young and adult L2 learners and young L1 learners, a clearer picture of the role of input and of innate predispositions for certain structural choices may emerge. The focus on multilingual contexts and a developmental perspective is also theoretically motivated, as we can test how generative models can be extended to data that have not played a core role in the development of generative theory (see especially Rothman et al. to appear; Lohndal et al. accepted).

This issue represents a small sample of the ongoing research within the group, and it has a special focus on Norwegian. A detailed overview of the members and the research within the group is available on the AcqVA website (http://site.uit.no/ acqva/). The four papers in the current issue all address core AcqVA matters, with child and/or adult Norwegian as the starting point. Work in the AcqVA group indeed centers around Norwegian, and many members of the group have a long tradition of studying this language, although a number of other languages are also included in our work. We briefly introduce each of the articles below and connect them to previous and ongoing work within the AcqVA group.

In their paper "A comparison of Norwegian and Spanish L1 acquisition of possessive constructions" Fábregas et al. compare the L1 acquisition of possessives in Norwegian and Spanish, finding non-target forms in children's production in both languages: In cases where there is more than one structural option for expressing a certain linguistic function, here, possessive relationships, children overuse the structure that is less syntactically complex, even when the less complex structure is less frequent than the more complex structure. The article illustrates in a very simple way that, although input frequency is an important factor in language acquisition, a successful account of the developmental trajectory cannot be given without taking into account linguistic factors. The authors argue that the relative complexity of the syntactic constructions in a certain domain determines the developmental trajectory, possibly even to a larger extent than frequency. This study is thematically closely connected to previous and ongoing studies within the AcqVA group, e.g., Westergaard and Bentzen (2007, 2010); Anderssen and Westergaard (2010, 2012); Westergaard (2008). The effects of frequency and complexity have been studied for other syntactic phenomena as well, such as subject and object placement (Anderssen et al. 2010, 2012). Further, the effects of frequency and complexity have been studied in different groups of speakers, such as L2 learners and heritage speakers of Norwegian, e.g., Anderssen et al. (2018b); Westergaard and Anderssen (2015). By studying these groups in parallel, we can now start to model the interaction between factors like linguistic complexity, current and previous input frequencies, cross-linguistic influence/transfer and age of onset.

Busterud et al.'s paper "The loss of feminine gender in Norwegian: A dialect comparison" investigates language change in gender assignment in a Norwegian dialect, showing a loss of feminine gender in young children acquiring the Trondheim dialect. They also relate this development to similar changes in other Norwegian dialects, including the Troms $\varnothing$ dialect. Grammatical gender is the target of several previous and ongoing studies within the AcqVA group, especially in the context of acquisition and change. A number of studies have been carried out, targeting L1/L2 learners and bilinguals from several languages, including 
Norwegian, Russian, German and Latvian, and using a variety of methods such as eye tracking, elicited production, and language games; see, e.g., Rodina and Westergaard (2012, 2015, 2017); Kupisch et al. (2013); Lohndal and Westergaard (2016); Lundquist et al. (2016); Urek et al. (2017); Lundquist and Vangsnes (2018). The results from these studies can provide us with information on how syntactic, morphological and lexical cues facilitate the building of a gender system, and also how gender features are stored and maintained in the monolingual and bilingual mind. This can give novel insight into language separation in bilinguals.

The only paper in the volume that builds on adult L1 data is "The form and position of pronominal objects with non-nominal antecedents in Scandinavian and German" by Bentzen and Anderssen, which discusses variation in the placement of pronominal objects. As has been shown in a number of recent studies (cf. Anderssen et al. 2012), object shift is not only conditioned by syntax (verb movement) and prosody/phonology (stressed vs. unstressed pronouns) (Holmberg 1986), but also by semantics and pragmatics (Andréasson 2008). Bentzen and Anderssen discuss pronominal objects in Norwegian that refer to events and propositions, and show that pronouns with non-nominal referents only shift if the event or proposition referred to is already established in the discourse. They show how this variation correlates with object pronoun choice in German, uncovering a systematicity in the apparent optionality which is paralleled in another Germanic language. This study indirectly relates to several AcqVA studies on the acquisition of Norwegian word order, especially in L1 acquisition (see Westergaard 2014 for an overview). As has been shown in previous studies (e.g., Anderssen et al. 2012), Norwegian children take a long time to acquire object shift, something that is presumably related to the complexity of the construction and the intricate interaction between syntax, discourse and phonology. A similar pattern has been found for L2 learners of Norwegian (Anderssen et al. 2018a).

The final article in the collection, "Language mixing within verbs and nouns in American Norwegian" by Riksem et al., focuses on language mixing in heritage speakers of Norwegian in America. This group of speakers has figured in a number of recent AcqVA studies (Lohndal and Westergaard 2016; Grimstad 2017; Riksem 2017; Eide and Hjelde 2015a; Westergaard and Anderssen 2015; Åfarli 2015a, b; Eide and Hjelde 2015b; Grimstad et al. 2014; Anderssen and Westergaard 2012; Westergaard and Lohndal 2019; Riksem 2018; Grimstad et al. 2018). Our growing understanding of their Norwegian competence provides valuable evidence concerning both the role of cross-linguistic influence and amount of input for building and maintaining a grammar, as well as the orgainization of bilingual grammars. The current article, like a number of other works referenced in this introduction, focuses on the organization of the grammar and the lexicon in multilingual speakers. As the authors show, the data from this group of speakers give us important information about how multiple languages are stored and employed in one mind, and how this can be handled in different theoretical frameworks.

As stated above, this issue covers just a small portion of the research that is carried out within the AcqVA group, but hopefully demonstrates convincingly that research which has a strong developmental focus while studying diverse speaker groups is both empirically motivated and theoretically rewarding. 


\section{References}

Anderssen, Merete, Kristine Bentzen, Yulia Rodina, and Marit Westergaard. 2010. The acquisition of apparent optionality: Word order in subject and object shift constructions in Norwegian. In Variation in the input: Studies on the acquisition of word order, ed. Merete Anderssen, Kristine Bentzen, and Marit Westergaard. Studies in Theoretical Psycholinguistics. Dordrecht: Springer.

Anderssen, Merete, Kristine Bentzen, Guro Busterud, Anne Dahl, Björn Lundquist, and Marit Westergaard. 2018a. Word order in L2 Norwegian: The case of subject and object shift. Nordic Journal of Linguistics 41 (3): 243-274. https://doi.org/10.1017/S0332586518000203.

Anderssen, Merete, Kristine Bentzen, and Yulia Rodina. 2012. Topicality and complexity in the acquisition of Norwegian object shift. Language Acquisition 19 (1): 39-72.

Anderssen, Merete, Björn Lundquist, and Marit Westergaard. 2018b. Crosslinguistic similarities and differences in bilingual acquisition and attrition: Possessives and double definiteness in Norwegian heritage language. Bilingualism: Language and Cognition 21 (4): 748-764. https://doi.org/10.1017/ S1366728918000330.

Anderssen, Merete, and Marit Westergaard. 2010. Frequency and economy in the acquisition of variable word order. Lingua 120 (11): 2569-2588. https://doi.org/10.1016/j.lingua.2010.06.006.

Anderssen, Merete, and Marit Westergaard. 2012. Tospråklighet og ordstilling i norske possessivkonstruksjoner. Norsk Lingvistisk Tidsskrift 30 (2): 310-337.

Andréasson, Maia. 2008. Not all objects are born alike-Accessibility as a key to pronominal object shift in Swedish and Danish. In Proceedings of the LFG08 Conference, 26-45, ed. Miriam Butt and Tracy Halloway King. Stanford: CSLI Publications.

Eide, Kristin Melum, and Arnstein Hjelde. 2015a. Borrowing modal elements into American Norwegian: The case of suppose(d). In Germanic heritage languages in North America: Acquisition, attrition and change, ed. Janne Bondi Johannessen and Joseph C. Salmons. Studies in Language Variation, 256-280. Amsterdam: John Benjamins Publishing Company.

Eide, Kristin Melum, and Arnstein Hjelde. 2015b. Verb second and finiteness morphology in Norwegian heritage language of the American Midwest. In Moribund Germanic heritage languages in North America: Theoretical perspectives and empirical findings, ed. B. Richard Page and Michael T. Putnam. Leiden: Brill.

Grimstad, Maren Berg. 2017. The code-switching/borrowing debate: Evidence from English-origin verbs in American Norwegian. Lingue e linguaggio 16 (1): 3-34. https://doi.org/10.1418/86999.

Grimstad, Maren Berg, Terje Lohndal, and Tor Anders Åfarli. 2014. Language mixing and exoskeletal theory: A case study of word-internal mixing in American Norwegian. Nordlyd 41 (2): 213-237.

Grimstad, Maren Berg, Brita Ramsevik Riksem, Terje Lohndal, and Tor Anders Åfarli. 2018. Lexicalist vs exoskeletal approaches to language mixing. The Linguistic Review 35 (2): 187-218.

Holmberg, Anders. 1986. Word order and syntactic features in the Scandinavian languages and English. Stockholm: Department of General Linguistics, University of Stockholm.

Kupisch, Tanja, D. Akpinar, and A. Stöhr. 2013. Gender assignment and gender agreement in adult bilingual and second language speakers of French. Linguistic Approaches to Bilingualism 3 (2): 150-179.

Lohndal, Terje, Jason Rothman, Tanja Kupisch, and Marit Westergaard. (accepted). Heritage language bilingualism and linguistic theory: The bidirectional benefits. Language and Linguistics Compass.

Lohndal, Terje, and Marit Westergaard. 2016. Grammatical gender in American Norwegian heritage language: Stability or attrition? Frontiers in Psychology 7: 344. https://doi.org/10.3389/fpsyg.2016. 00344.

Lundquist, Björn, Yulia Rodina, Irina Sekerina, and Marit Westergaard. 2016. Gender change in Norwegian dialects: Comprehension precedes production. Linguistics Vanguard 2 (1): 69-83. https://doi.org/10.1515/lingvan-2016-0026.

Lundquist, Björn, and Øystein A. Vangsnes. 2018. Language separation in bidialectal speakers: Evidence from eye tracking. Frontiers in Psychology 9: 1394. https://doi.org/10.3389/fpsyg.2018.01394.

Riksem, Brita Ramsevik. 2017. Language mixing and diachronic change: American Norwegian noun phrases then and now. Languages 2 (2): 100. https://doi.org/10.3390/languages2020003.

Riksem, Brita Ramsevik. 2018. Language mixing in American Norwegian noun phrases. Trondheim: NTNU.

Rodina, Yulia, and Marit Westergaard. 2012. A cue-based approach to the acquisition of grammatical gender in Russian. Journal of Child Language 39 (5): 1077-1106. 
Rodina, Yulia, and Marit Westergaard. 2015. Grammatical gender in Norwegian: Language acquisition and language change. Journal of Germanic Linguistics 27 (2): 145-187.

Rodina, Yulia, and Marit Westergaard. 2017. Grammatical gender in bilingual Norwegian-Russian acquisition: The role of input and transparency. Bilingualism: Language and Cognition 20 (1): 197-214.

Rothman, Jason, Fatih Bayram, Tanja Kupisch, Terje Lohndal, and Marit Westergaard. to appear. Generative approaches to second language (L2) acquisition and advanced L2 proficiency. In The handbook of advanced proficiency in second language acquisition, eds. Alessandro G. Benati, and Paul Malovrh. New York: Blackwell/Wiley.

Urek, Olga, Marit Westergaard, and Agrita Taurina. 2017. Acquisition of grammatical gender in LatvianRussian bilinguals. Paper presented at the International Symposium on Bilingualism 11, Limerick, 2017-06-11-2017-06-16.

Westergaard, Marit. 2008. Acquisition and change: On the robustness of the triggering experience for word order cues. Lingua 118 (12): 1841-1863. https://doi.org/10.1016/j.lingua.2008.05.003.

Westergaard, Marit. 2014. Linguistic variation and micro-cues in first language acquisition. Linguistic Variation 14 (1): 26-45. https://doi.org/10.1075/lv.14.1.02wes.

Westergaard, Marit, and Merete Anderssen. 2015. Word order variation in Norwegian possessive constructions: Bilingual acquisition and attrition. In Germanic heritage languages in North America: Acquisition, attrition and change, ed. Janne Bondi Johannessen, and Joseph C. Salmons. Studies in Language Variation. Philadelphia: John Benjamins Publishing Company.

Westergaard, Marit, and Kristine Bentzen. 2007. The (non-) effect of input frequency on the acquisition of word order in Norwegian embedded clauses. In Frequency effects in language acquisition. Defining the limits of frequency as an explanatory concept, 271-306. Berlin: Mouton de Gruyter.

Westergaard, Marit, and Kristine Bentzen. 2010. Word order and finiteness in the acquisition of English and Norwegian wh-questions. Boston University Conference on Language Development. Proceedings (pp. 457-467).

Westergaard, Marit, and Terje Lohndal. 2019. Verb second word order in Norwegian heritage language: Syntax and pragmatics. In Variable properties in language: Their nature and acquisition, eds. David Lightfoot, and Jon Havenhill. Washington, DC: Georgetown University Press.

Åfarli, Tor A. 2015a. Hybrid verb forms in American Norwegian and the analysis of the syntactic relation between the verb and its tense. In Germanic Heritage Languages in North America, eds. Janne Bondi Johannessen, and Joseph C. Salmons, 161-177. Amsterdam/Philadelphia: John Benjamins.

Afarli, Tor A. 2015b. A syntactic model for the analysis of language mixing phenomena: American Norwegian and beyond. In Moribund Germanic heritage languages in North America eds. B. Richard Page, and Michael T. Putnam, 12-33. Leiden: Brill.

Publisher's Note Springer Nature remains neutral with regard to jurisdictional claims in published maps and institutional affiliations. 